\title{
Airway management in patient with retractable scar in neck: a case report
}

\begin{abstract}
44-year-old male patient hospitalized 4 months ago for presenting a $25 \%$ body surface burn in thoracic limbs and face; as well as airway. Developing a retractable scar in the anterior neck which progressed, so it was scheduled by plastic surgery service for scar release plus the application of anterolateral free thigh flap.

Anesthetic management was given with general anesthetic with intubation in an awake patient with flexible fibroscopy, based on fentanyl and intravenous propanidid, once vocal cords are crossed with the fibroscope endotracheal tube is introduced and balanced general anesthesia is provided. Surgical anterolateral free thigh flap procedure ends, endotracheal tube is removed, without complications. In the late postoperative period, the patient presents favorable evolution with adequate flexion and cervical extension with the use of the flap.
\end{abstract}

Keywords: burn, difficult airway, awake intubation, retractable scar, propanidid
Volume 12 Issue 3 - 2020

\author{
Barbabosa Balanzario Manuel Alejandro, \\ Sánchez López Roberto Alejandro, Flores \\ Uribe Cynthia Edith, Gil López Jorge \\ Guillermo, Carriola Zamilpa Carlos Ignacio, \\ Puente Solorio Armando, Cruz Martinez \\ Cynthia \\ Anesthesiology Service of the Medical Center Lic, Adolfo \\ LópezMateos, Institute of Health of the State of Mexico
}

Correspondence: Manuel Alejandro BarbabosaBalanzario, Anesthesiology Service of the Medical Center Lic, Adolfo LópezMateos, Institute of Health of the State of Mexico, Toluca, Mexico,Tel 72257|6794, Email manalebarbal@gmail.com

Received: January 28, 2020 | Published: May 5, 2020

\section{Introduction}

The airway management of patients with neck burn contracture requires skill and competence. The airway can be difficult for one or several of the following reasons: restricted mouth opening (healed mouth angles), obliterated nostrils, decreased oropharyngeal space, fixed neck flexion deformity, limited atlanto-occipital joint extension, reduction of the submandibular space or alteration of the tracheal position.

Onah $^{1}$ has described a clinical classification system for postburn mentosternal contractures comprising four major groups based on the location of the contracting band and extent of flexion or extension away from the anatomical position of the neck and jaws. Each group is further sub-classified based on the contracting segment width. Jeong et al. ${ }^{2}$ modified the Onah classification (Table 1 ) and found significant correlation between modified Onah class $2 \mathrm{~b}$ and 3 and Cormack grade 3 and 4 laryngoscopic views (sensitivity and specificity $86.0 \%$ and $84.9 \%$, respectively). The application of the modified Onah class can reduce the frequency of an unanticipated failure to visualize laryngeal structures and potential unnecessary interventions related to overprediction of airway difficulty in patients with post-burn mentosternal contractures.

Fixed flexion deformity results in nonalignment of the oral, pharyngeal and laryngeal planes for intubation. In a patient undergoing multiple surgical procedures, the release of neck contracture is performed first to ensure easier control of the airways in subsequent surgeries. Strategies for airway management, intraoperative problems and concerns in extubation of patients with neck of patients with retractable scar. ${ }^{3}$ The scarce information in patient with retractable scar in neck and almost null for the use of propanidid in awake intubation mainly based on data from published randomized clinical trials and case reports that were identified through the Pubmed, Medline and Google Scholar databases.
Table I ThemodifiedOnah classification ${ }^{2}$

Type Degree of contracture
Mild anterior contracture: the patient is able to flex the neck
and bring the neck and jaws to the anatomical position while
erect
a) Narrow, $<2$ fingerbreadths
broad, $>2$ fingerbreadths
Moderate anterior contracture: attempts at extension away
from the anatomical position result in a significant pull at the
lower lip
Narrow, <2 fingerbreadths
B) $\begin{aligned} & \text { Broad, }>2 \text { fingerbreadths } \\ & \text { b) Severe anterior contracture: the patient's neck is contracted } \\ & \text { in the flexed position and the chin is occasionally restrained } \\ & \text { down to the anterior trunk The patient is unable to reach } \\ & \text { anatomical position of the neck and jaws }\end{aligned}$

\section{Case report}

44-year-old male patient hospitalized 4 months ago for presenting a $25 \%$ body surface burn in thoracic limbs and face; as well as airway. Developing a retractable scar in the anterior neck which progressed to a point where food intake was difficult due to access to the mouth. He avoided the conversation due to the difficulty of speech, his limited ability to communicate, food intake and the appearance of his face, especially that of his mouth and neck, forced him to seek medical attention.

At the first physical examination(Figure 1-3), the patient is shown with a $44 \mathrm{~mm}$ horizontal and $20 \mathrm{~mm}$ vertical oral openingwith 
lower lip retraction (Figure 4)grade III oral opening scale and grade IV Mallampatti-Samsoon-Young scale with a limited mandibular protuberance keeping lower incisors in front of upper incisors, as well as a facial surface with epithelized mixed second degree burns, in the anterior cervical region, a retractable scar that prevents neck extensionconditioning Bellhouse-Doré scale grade IV, scales such as Patil-Aldreti, sterno-mental distance and neck circumference could not be measured by anatomical distortion, anterior chest burns with adequate epithelialization, preoperative tests revealed no nutritional deficiencies, a chest $\mathrm{x}$-ray is performed presenting cervical flexion (Figure 5). Therefore, computed tomography is taken, revealing presents an increase in oral, laryngeal and pharyngeal angles (Figure 6), corroborated in the reconstruction of soft tissue (Figure 7), a vascular reconstruction is also performed for surgical planning (Figure 8); so it was scheduled by plastic surgery service for scar release plus the application of anterolateral free thigh flap.

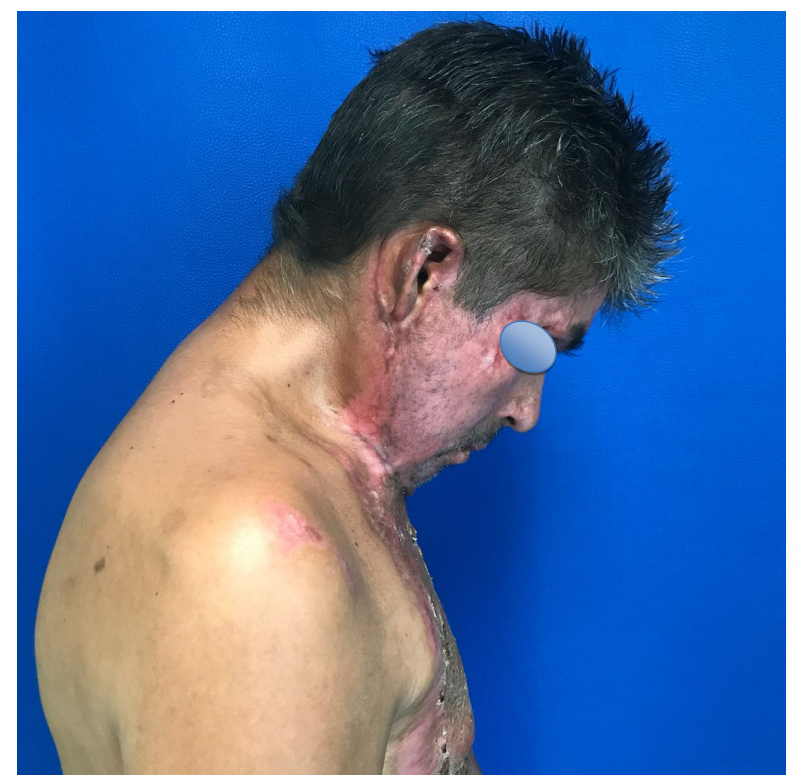

Figure I

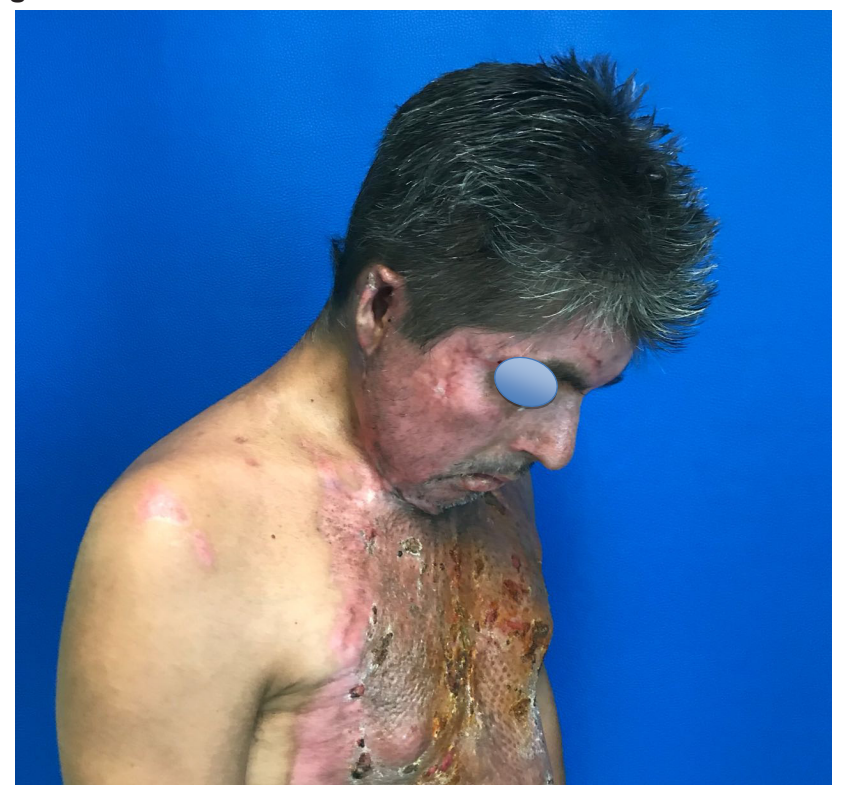

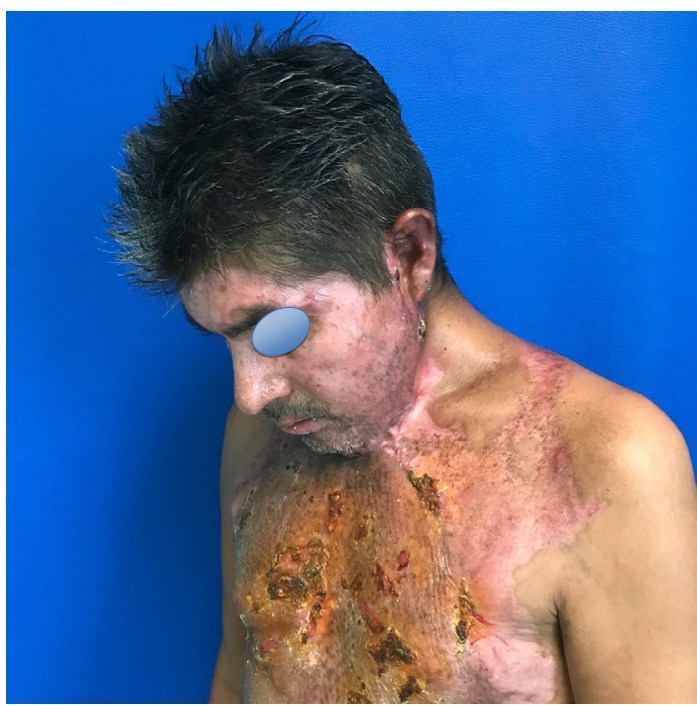

Figure 3

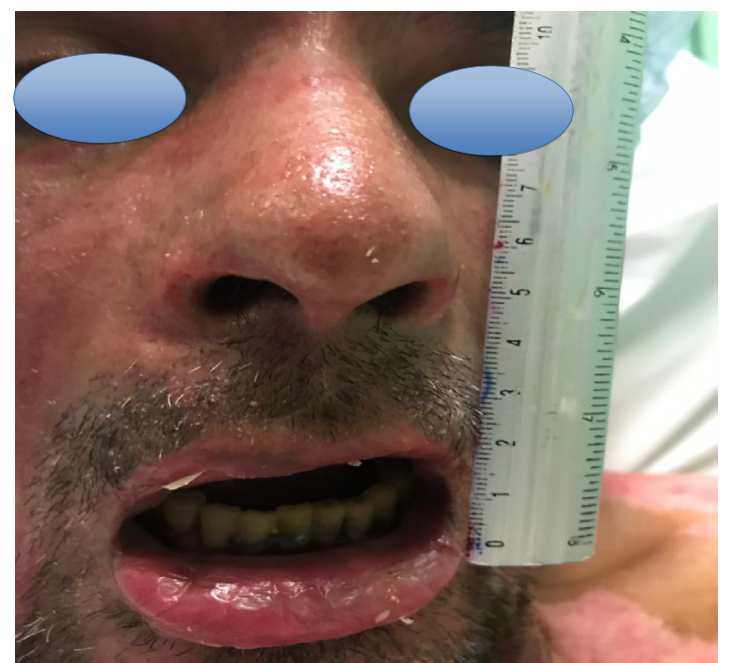

Figure 4

\section{Anesthetic management}

We give general anesthetic with intubation in an awake patient with flexible fibroscopy; a patient is placed in a sitting position, nebulization with $2 \%$ simple lidocaine is applied for $10 \mathrm{~min}$ and simple lidocaine is administered in swabs through nostrils. Antisialog with atropine and analgesia based on fentanyl and intravenous propanidid is given latency and flexible fibroscope is introduced through the right nostril, patient remains in spontaneous ventilation, glottis is located, simple lidocaine is instilled $2 \%$ in a spray-as-yougo technique and once vocal cords are crossed with the fibroscope endotracheal tube is introduced(Figure 9), capnography line is observed, induced and balanced general anesthesia is provided(Figure 10). Surgical anterolateral free thigh flap procedure ends (Figure $11,12)$, endotracheal tube is removed, without complications. In the late postoperative period, the patient presents favorable evolution with adequate flexion and cervical extension with the use of the flap (Figure 13-15).

Figure 2 


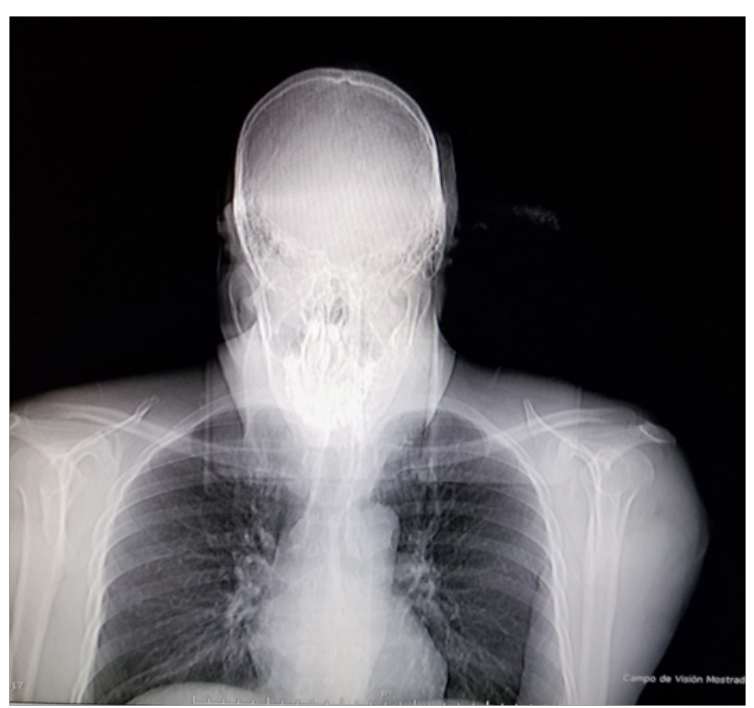

Figure 5

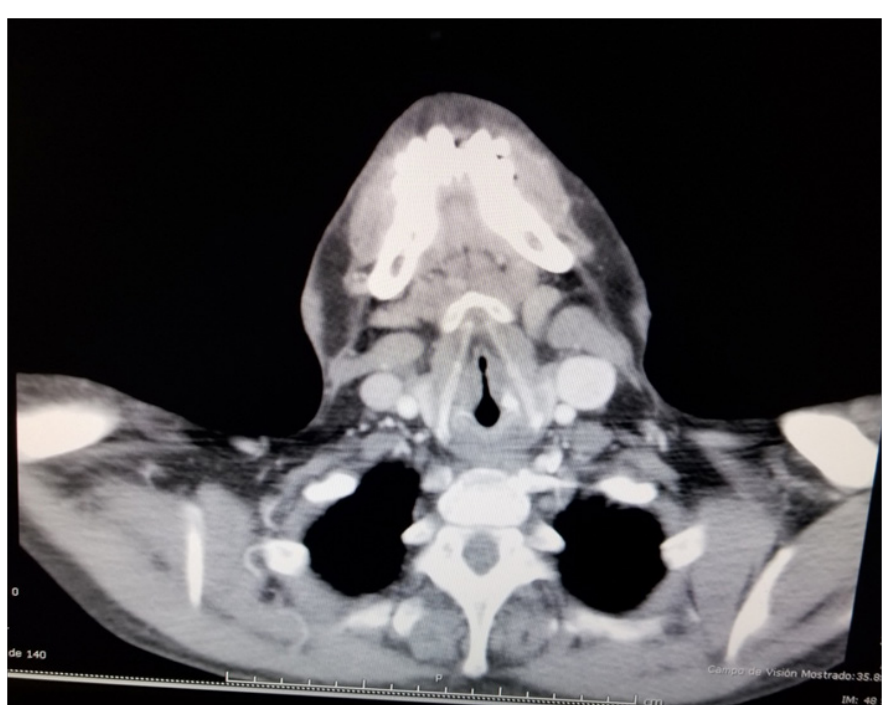

Figure 6

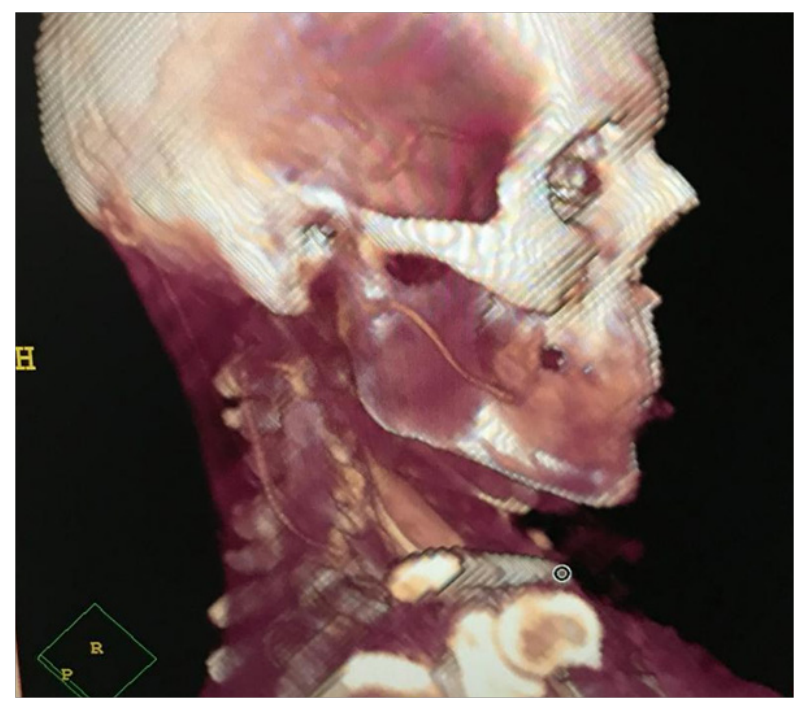

Figure 7

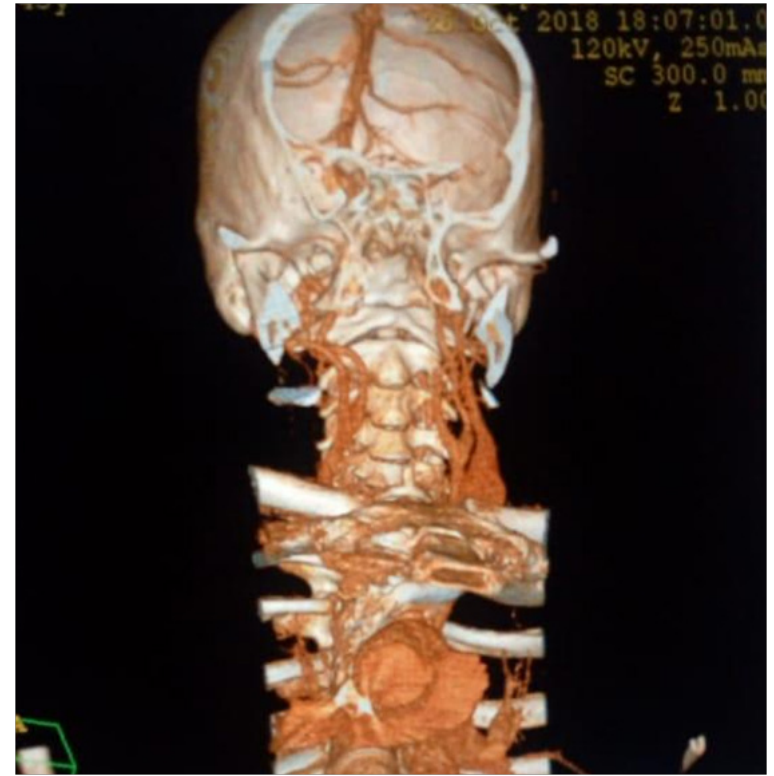

Figure 8

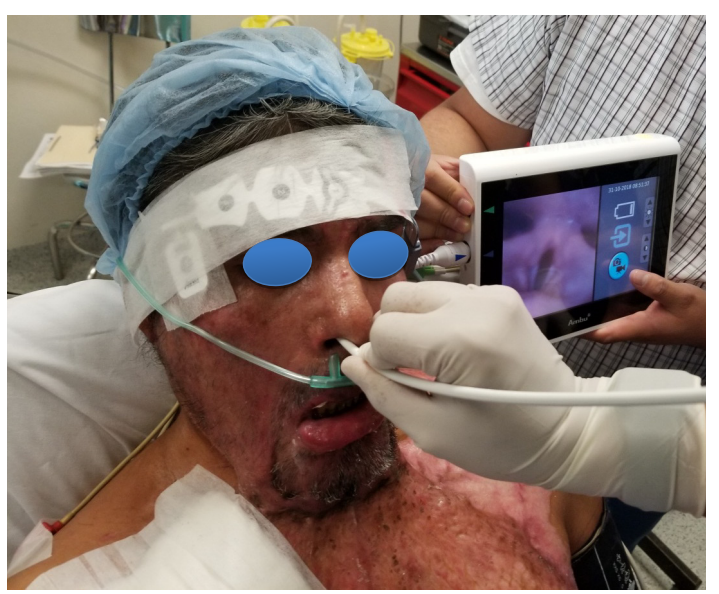

Figure 9

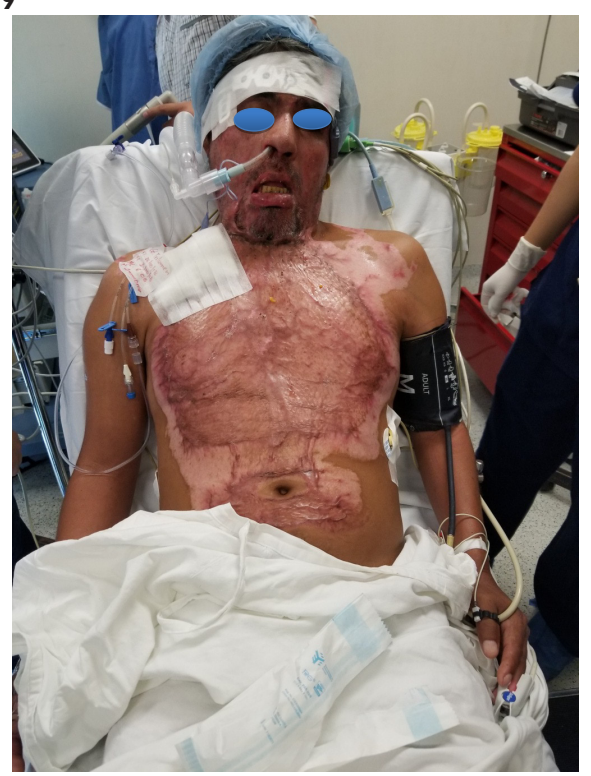

Figure 10

Citation: Alejandro BBM, Alejandro SLR, Edith FUC, et al.Airway management in patient with retractable scar in neck: a case report.J Anesth Crit Care Open Access. 2020; I2(3):84-90. DOI: I0.15406/jaccoa.2020.12.00437 


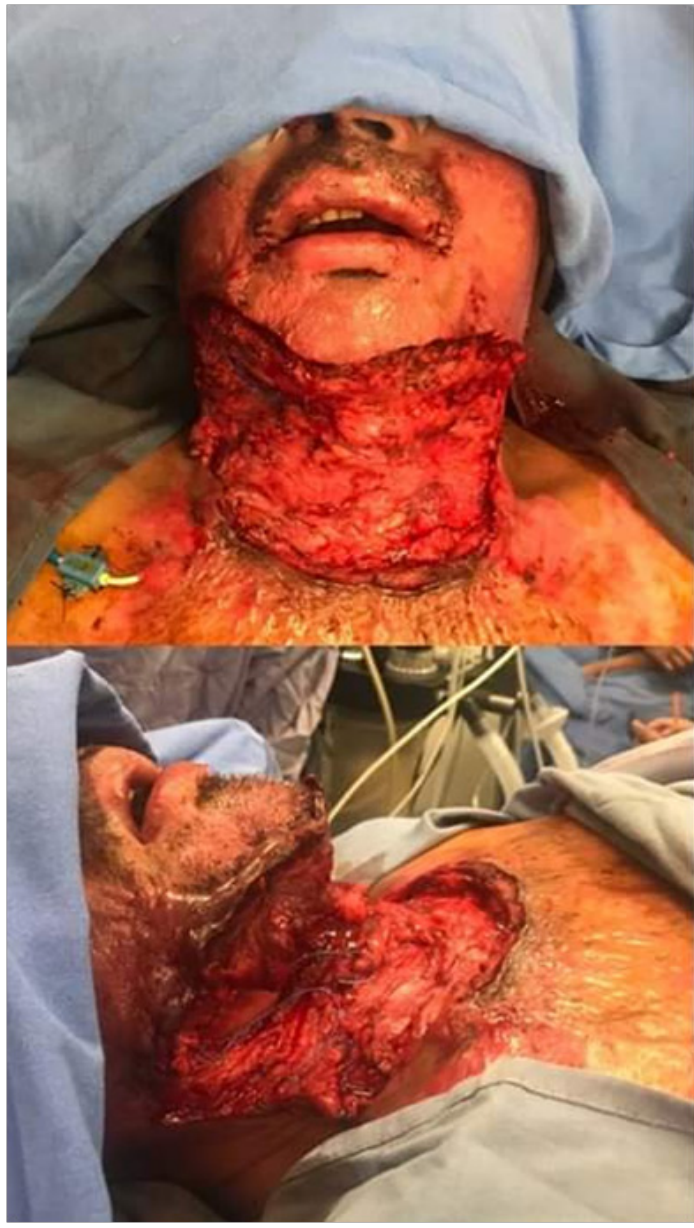

Figure I I

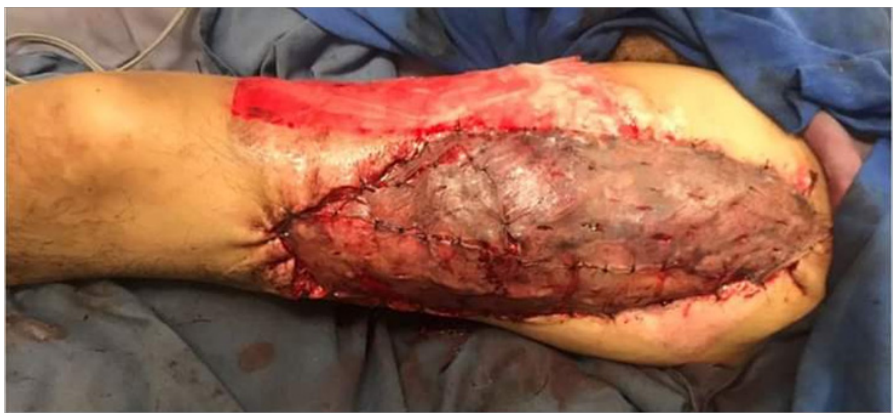

Figure 12

\section{Discussion}

The patient had late burn complications, that is, contractures. The anesthesiologist's main concern is the potential risk of the difficult airway. We did not consider retrograde intubation or tracheotomy because the anterior structures of the neck, including the larynx, trachea and carotid arteries were neither identifiable nor palpable. ${ }^{4}$

Airway management of patients with neck burn contracture is a challenge for the anesthesiologist. Patient evaluation includes history, physical examination and airway. A safe approach to the management of the airways of a patient with a moderate to severe retractable neck scar is to secure the airway with the patient awake. The anesthesiologist must have a previously planned strategy for intubation of the difficult airway. ${ }^{5}$

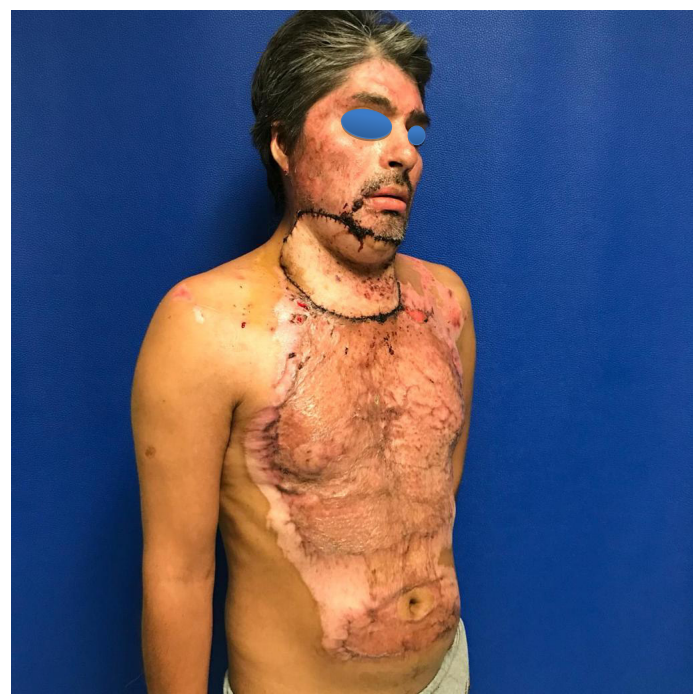

Figure 13

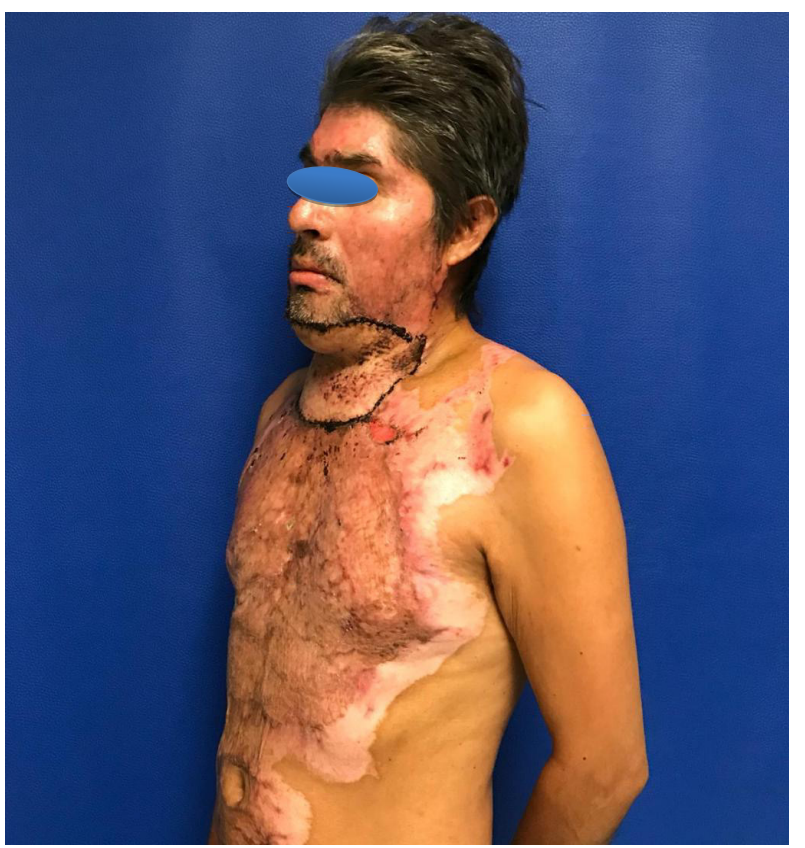

Figure 14

The recommended options for airway management of these patients include, lidocaine (1-4\%) is most commonly used for airway anesthesia for awake intubation. It is important to be cognizant of the amount of lignocaine used (toxic plasma levels $>5 \mathrm{mg} / \mathrm{ml}$ ) as it is quickly absorbed from the oral and tracheal mucosa. Total lidocaine dose should be limited to $8.2 \mathrm{mg} / \mathrm{kg} .{ }^{6}$ Use of such high doses of lignocaine is safe as the drug is administered in fractional doses at different sites in the airway over a period of time.

Topical anesthesia is the mainstay of airway preparation in patients with burn contracture of the neck and can be achieved by use of aerosol sprays, nebulization, gargling or spray-as-you-go technique (SAYGO). Nebulization involves inhalation of vapour $(4 \mathrm{ml}$ of lidocaine $4 \%$ ) through the nose or mouth for nasal or oral intubation, 
respectively.Cotton-tipped nasal pledgets soaked in 2-4\% lidocaine are placed (for $15 \mathrm{~min}$ for optimal effect). Alternatively, $2 \%$ lidocaine jelly can be squeezed into each nostril and the patient is asked to sniff vigorously. The patient is instructed to gargle with viscous lidocaine $2 \%$. The solution is expectorated to avoid excess local anesthetic absorption. In the SAYGO technique, the fiberscope is advanced in the hypopharynx where the glottic structures are visualized. Lidocaine $2 \%$ solution ( $1 \mathrm{ml}$ lignocaine and $9 \mathrm{ml}$ air drawn in a 10-ml syringe) is injected via the working channel of the fiberscope on the mucosa Alternatively, an epidural catheter (introduced through the side port) can be threaded out of the end of the scope and lignocaine injected onto the cords. The catheter can also be placed through the cords allowing a further dose to be injected below the cords. The SAYGO technique is particularly useful in patients with patients with burn contracture of neck as it is usually not possible to perform nerve blocks to anesthetize the upper airway.

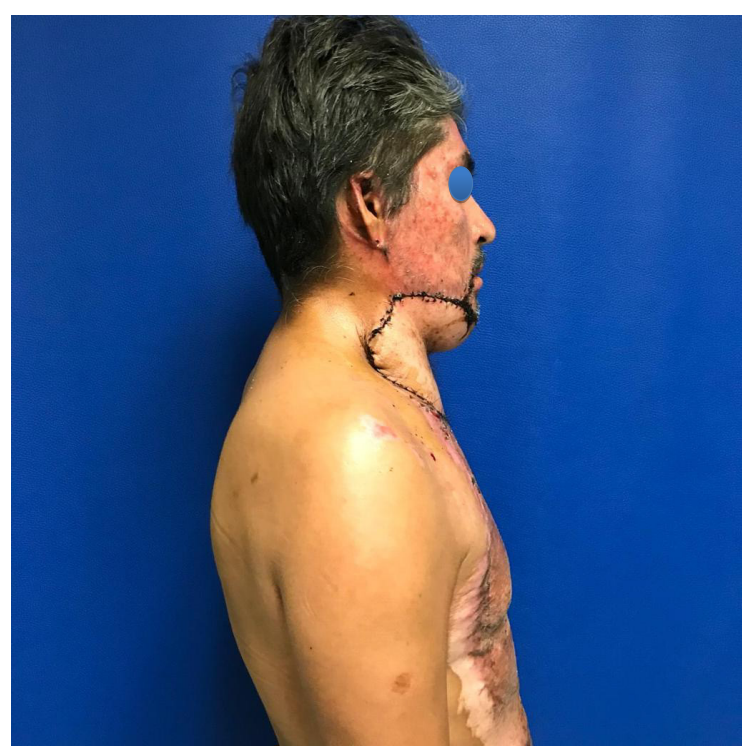

Figure 15

Nerve blocks of superior laryngeal and translaryngeal nerve blocks are usually not possible in patients with burn contracture of the neck due to lack of access to the anterior and lateral neck, hyoid bone and limited or no neck extension.

Awake fiberoptic-guided intubation in patients with burn contracture of the neck location of the glottis and insertion of the fiberscope into the trachea can be difficult because of the fixed flexion deformity of the neck and distortion of upper airway structures by the fibrotic scar. Maneuvers that facilitate glottis visualization, such as jaw thrust and head extension may not be possible in such patients. Sometimes, because of extreme flexion deformity of the neck, it may be very difficult or even impossible to advance the tracheal tube over the scope into the trachea when the fiberscope has been successfully placed in the trachea. An important reason for this difficulty is deviation of the course of the tube from that of the fiberscope toward the epiglottis, arytenoids cartilage, pyriform fossa or esophagus. ${ }^{7}$ ${ }^{9}$ Esophageal intubation may occur despite correct placement of the fiberscope into the trachea. ${ }^{10,11}$ To overcome difficulty with railroading (advancing a tracheal tube over a fiberscope) the tube, the following is recommended: reducing the gap between the fiberscope and trachea, use of flexible tube and $90^{\circ}$ anti-clockwise rotation of the tracheal tube. ${ }^{7}$ Compared to a polyvinyl chloride (PVC) tube, a flexible tracheal tube is easier to advance over the fiberscope as it can change direction more easily to follow the course of the fiberscope. ${ }^{12,13}$ Warming a PVC tracheal tube is not recommended in patients with burn contracture of the neck. A warm PVC tracheal tube is softer and hence more likely to get kinked in the acutely angled naso- or oro-pharynx of the patient with extreme flexion deformity of the neck. ${ }^{14}$ For oral intubation, airway intubators such as the Berman, ${ }^{15}$ Ovassapian ${ }^{16}$ and Williams ${ }^{17}$ are available. However, in patients with microstomia (cicatrisation following oral burns), these airways may not be accommodated through the narrowed inter-incisor gap. The cut barrel of a 10-ml syringe has been used as a bite-guard during oral awake fiberopticguided tracheal intubation in a patient with limited mouth opening. ${ }^{18}$ A patient with obliterated nares, extreme microstomia and severely limited neck extension was managed by awake oral fiberoptic-guided intubation aided by a Williams airway intubator ${ }^{19}$ Assessing the correct airway-intubator size is important. The measured length from the lips to the back of the tongue on lateral neck X-ray was used to determine the airway size ${ }^{19} \mathrm{~A}$ similar patient was managed by awake oral fiberoptic intubation aided by Berman's airway that allows the tracheal tube to pass directly through its channel into the glottis. ${ }^{20}$

With the supraglottic airway devices, the Intubating Laryngeal Mask Airway-FastrachTM (ILMA) canbe used for ventilation and to facilitate either blind or fiberoptic guided tracheal intubation. In patients with patients with burn contracture of the neck in whomfacemask ventilation is expected to be difficult, the ILMA maybe inserted after topical anesthesia of the upper airway. Ifintubation through the ILMA is unsuccessful, the followingmaneuvers may be performed; (1) up-down maneuver (slowlywithdrawing the inflated cuff from the pharynx $5-6 \mathrm{~cm}$ andthen reinserting it ${ }^{21}$ which repositions a down-foldedepiglottis during blind ILMA use); (2) optimization maneuver ${ }^{22}$ adjusting the ILMA position until optimal seal is obtained;(3) extension maneuver ${ }^{23}$ (pulling the handle of the ILMA backtoward the operator); (4) Chandy maneuver ${ }^{23}$ (this maneuverconsists of two sequential steps). The first step enables optimalalignment of the laryngeal aperture and the bowl of the mask.

The metal handle is used to rotate the device in the sagittalplane to establish optimal ventilation with minimal resistanceto bag ventilation and minimal audible leaks during manualventilation. In the second step, just before blind intubation theLMA-Fastrach is slightly lifted (but not tilted) away from theposterior pharyngeal wall using the metal handle. Thisfacilitates the smooth passage of the endotracheal tube into the trachea; (5)change of size of ILMA.

In patients with extreme flexion of the neck with the mouthopening directed inferiorly, it may not be possible to introducethe ILMA in the conventional manner. The hypotenuse of thetriangle formed on joining the tip of the mouth portion with themachine end of the ILMA is the minimum distance requiredbetween the hard palate and the most anterior part of thepatient's chest for successful ILMA placement. ${ }^{24}$ Following trachealintubation through the ILMA, removal of the ILMA with use ofthe stabilizer rod has to be performed with utmost care toavoid accidental extubation. Pushing the tracheal tube furtherinto the trachea before attempting removal of ILMA can helpprevent inadvertent extubation. ${ }^{24}$ At times it might beprudent to leave the ILMA and tube in place until after thecontracture has been released. ${ }^{24}$

The Laryngeal Mask Airway (LMA) has a role in themanagement of the difficult airway as a definitive airway oras an aid to tracheal intubation, either blindly or with fiberopticguidance. Blind passage of a tube exchanger or a bougie into thetrachea can be attempted 
followed by removal of the LMA andintubation with a tracheal tube over the guiding device. ${ }^{23}$ TheLMA can be used successfully as a bridge to restore the airway ina cannot ventilate cannot intubate situation. ${ }^{25}$ However, the LMA may not always be correctly placed because ofanatomical abnormalities and may be displaced by intraoperative position changes. ${ }^{26}$ Other supraglottic devices such asthe ProSeal LMA, I-gel and laryngeal tube may be similarly used.A Combitube was successfully used in a patient with patients with burn contracture of the neck with limited mouth opening and tracheal stenosis thatprecluded tracheal intubation. ${ }^{27}$

Intubation by direct laryngoscopy is practiced when maskventilation is expected to be satisfactory following inductionof anesthesia (intravenous or inhalational) and intubation isexpected to be difficult but possible. Preoxygenation isimportant. ${ }^{4}$ In cases where difficulty is anticipated,intubation or laryngoscopy is performed without use ofneuromuscular blocking agents. The combination of fentanyl $(2 \mathrm{mg} /$ $\mathrm{kg})$ and midazolam $(0.03 \mathrm{mg} / \mathrm{kg})$ followed 5 min later bypropofol $(2.5 \mathrm{mg} / \mathrm{kg})$ provides acceptable intubating conditionsin a majority of patients. ${ }^{4}$ If intubation is judged to beeasy, (favorable Cormack grade), neuromuscular block can beprovided by rocuronium $0.9 \mathrm{mg} /$ $\mathrm{kg}$. External laryngeal manipulation,use of a smaller than regular sized tracheal tube,stylet, bougie and McCoy laryngoscope blade can facilitateintubation. The use of a two-person intubation technique isparticularly useful in this setting, wherein, one anesthesiologist performs laryngoscopy and optimal laryngeal manipulation to obtain the best possible view of the glottis and a secondanesthesiologist intubates the trachea. In case of unilateralscars, the epiglottis and vocal cords are pulled toward the sideof the scar and the laryngoscope should be advancedipsilaterally toward the direction of the scar. ${ }^{26}$ Use of alightwand in patients with patients with burn contracture of the neck is hampered by thick scartissue that may obscure light and result in esophagealintubation.

Video-assisted rigid laryngoscopy or video laryngoscopy (VL) isa useful adjunct to facilitate tracheal intubation in patientswith patients with burn contracture of the neck. While direct laryngoscopy is associated withfailure when a laryngeal view cannot be obtained, VLfrequently overcomes this obstacle. However, difficultiesmay be encountered in advancing the tracheal tube towardthe laryngeal view of the video-monitor. This disadvantagecan be overcome by using fiberoptic bronchoscopy as aguidewire under VL view. ${ }^{29}$ Chong et al. $^{30}$ reported successful airway management Awake intubation usingfiberopticbronchoscopy under GlideScope $\square$ Video laryngoscope guide with severe patients with burn contracture of the neck.

Tumescent anesthesia (TA) involves subcutaneous infiltration of a large volume of very dilute lignocaine (as low as $0.05 \%$ or $0.1 \%$ ) and adrenaline $(1: 200,000)$. This allows administration ofup to $55 \mathrm{mg} /$ $\mathrm{kg}$ of lidocaine. ${ }^{31} \mathrm{TA}$ has been used safely forharvesting skin grafts, liposuction and patients with burn contracture of the neck release. Factors that contribute to the safety of TA include dilute solution of lidocaine, a relatively avascular subcutaneous/fibrous tissue, lipid solubility of lignocaine, vasoconstrictiveeffect of adrenaline and compression of vasculature frominfusion of a large volume of solution. ${ }^{32}$ The solution isinfiltrated along the incision line and into the surroundingtissues. Safe and quick surgical neck contracture releasefacilitates tracheal intubation. Neck contracture release priorto intubation was first described by Tanzer ${ }^{33}$ in 1964 whosuggested release of the inferior half of the neck under localanesthesia when difficulties are anticipated. Further releasecan then follow successful intubation. The interval betweenincision and tube insertion may be rather critical.

The preparation of our patient includes an explanation of the proposed procedure, sedation, administration of antisialog and regional airway anesthesiathis had to be provided in a personalized way since access for external infiltration of local anesthetic to the superior laryngeal nerve or transtracheal application of local anesthetic was incapable due to the anatomical modifications that conditioned the scar tissue. We opted for a nasal route considering the clinical characteristics of our patient, nebulizations with lidocaine as well as lidocaine impregnated swabs in the nasal passages with an adequate approach to the airway and visualization of the airway with spray-as-you-go technique under sedation with fentanyl and adjuvant propanidid(3 a $5 \mathrm{mg} / \mathrm{kg}$ )it increases the respiratory volume approximately $300 \%$ and the respiratory frequency like $20 \%$. This hyperventilation persists on average 40 seconds, followed by hypoventilation that lasts two to five seconds. After this, the respiratory volume per minute, simultaneously with the start of respiratory stimulation, lowers blood pressure and increases the pulse rate. Systolic blood pressure decreases $10 \%$ and diastolic blood pressure $15 \%$, while the pulse increases on average to $15 \%$, returning to normal in two minutes, ${ }^{34}$ with adequate tolerance to the procedure without reviewing the literature on this drug in this type of patients.

\section{Conclusion}

The anesthetic management of this patient with burns and contractures presented a special challenge to the intubation skill of the anesthetist. It demonstrated the need for careful approach to the problem of difficult airway under anesthesia.Propanidid is an ultrashort acting agent, useful in anesthesia for sedation and induction, it has shown us its safety, efficacy and versatility in short procedures such as intubation in the awake patient. This case demonstrated the useful role played by fibroscope in the management of difficult airway with particular reference to patients with retractable scar in neck.

\section{References}

1. Onah II. A classification system for postburn mentosternal contractures. Arch Surg. 2005;140:671-675.

2. Jeong IM, Seo WG, Woo CH, et al. Prediction of difficult intubation in patients with postburn sternomental contractures: modified Onah class. Korean J Anesthesiol. 2009;57(3):290-295.

3. Prakash S, Mullick P. Airway management in patients with burn contractures of the neck. Burns. 2015;41(8):1627-1635.

4. Apfelbaum JL, Hagberg CA, Caplan RA, et al. Practice guidelines for management the difficult airway: an updated report by the American Society of Anesthesiologists Task Force on Management of the Difficult Airway. Anesthesiology. 2013;118(2):251-270.

5. Thomas J Caruso, Luke S Janik, Gennadiy Fuzaylov. Airway management of recovered pediatric patients with severe head and neck burns: a review. Paediatr Anaesth. 2012;22(5):462-468.

6. British Thoracic Society guidelines on diagnostic flexible bronchoscopy. Thorax. 2001;56(Suppl. I):i1-21.

7. Asai T, Shingu K. Difficulty in advancing a tracheal tube over a fibreoptic bronchoscope: incidence, causes and solutions. Br J Anaesth. 2004;92(6):870-881 
8. Katnelson T, Frost EAM, Farcon E, Goldiner PLet al. When the endotracheal tube will not pass over the flexible fiberoptic bronchoscope. Anesthesiology. 1992;76(1):151-152.

9. Schwarz D, Johnson C, Roberts J. A manoeuvre to facilitate flexible fiberoptic intubation. Anesthesiology. 1989;71(3):470-471.

10. Koga K, Asai T, Latto IP, et al. Effect of size of a tracheal tube and the efficacy of the use of the laryngeal mask for fibrescope-aided tracheal intubation. Anaesthesia. 1997;52(2):131-135.

11. Moorthy SS, Dierdorf SF. An unusual difficulty in fiberoptic intubation Anesthesiology. 1985;63(2):229.

12. Calder I. When the endotracheal tube will not pass over the flexible fiberoptic bronchoscope. Anesthesiology. 1992;77(1):398.

13. Hakala P, Randell T, Vali H. Comparison between tracheal tubes for orotracheal fibreoptic intubation. Br J Anaesth. 1999;82(1):135-136.

14. Prakash S, Kumar A, Kumar M, et al. Successful detection and management of kinked tracheal tube in a patient with severe post-burn contracture of the neck. Indian J Anaesth. 2013;57(1):90-91.

15. Berman RA. A method for blind oral intubation of the trachea or esophagus. Anesth Analg. 1977;56(6):866-887.

16. Ovassapian A. Fiberoptic endoscopy and the difficult airway. 2nd ed New York: Lipincott-Raven; 1996.

17. Williams RT, Maltby JR. Airway intubator. Anesth Analg. 1982;61(3):309.

18. Gupta P, Talwar V, Verma S, et al. Modified mouth prop for orotrachea fibreoptic intubation. J Anaesthesiol Clin Pharmacol. 2006;22:65-67.

19. Sahajanandhan R, Saravanan P, Ponniah M, et al. Post-burn contracture neck with extreme microstomia and fibrosed obliterated nose: a unique airway challenge. Natl Med J India. 2010;23(5):281-282.

20. Kaur KP, Taxak S, Hooda S, et al. Airway management of post burn contracture neck - an anaesthesiologist's challenge. Egypt J Anaesth. 2012;28:233-236

21. Brimacombe J. Laryngeal mask anesthesia: principles and practice. 2nd ed. Philadelphia: WB Saunders; 2005:166.

22. Komatsu R, Nagata O, Kamata K, et al. The intubating laryngeal mask airway allows tracheal intubation when the cervical spine is immobilized by a rigid collar. Br J Anaesth. 2004;93:655-659.
23. Ferson DZ, Rosenblatt WH, Johansen MJ, et al. Use of the intubating LMA-Fastrach in 254 patients with difficult-to-manage airways. Anesthesiology. 2001;95:1175-1181.

24. Kumar R, Prashast, Wadhwa A, et al. The upside down intubating laryngeal mask airway: a technique of cases of fixed flexed neck deformity. Anesth Analg. 2002;95(5):1454-1458.

25. Jeong IM, Seo WG, Woo CH, et al. Prediction of difficult intubation in patients with postburn sternomental contractures: modified Onah class. Korean J Anesthesiol. 2009;57(3):290-295

26. Han TH, Teissler H, Han RJ, et al. Managing difficult airway in patients with post-burn mentosternal and circumoral scar contractures. Int J Burn Trauma. 2012;2(2):80-85.

27. Hagberg CA, Johnson S, Pillai D. Effective use of the esophageal tracheal Combitube following severe burn injury. J Clin Anesth. 2003;15(6):463466

28. Prakash S, Arora D, Prakash S, et al. A combination of fentanyl midazolam-propofol provides better intubating conditions than fentanyllignocaine-propofol in the absence of neuromuscular blocking agents Acta Anaesthesiol Scand. 2006;50(8):999-1004.

29. Park CD, Lee HK, Yim JY, et al. Anesthetic management for a patient with severe mentosternal contracture: difficult airway and scarce venous access - a case report. Korean J Anesthesiol. 2013;64:61-64.

30. Chong-Doo Park, Hye-Kyoung Lee, Ji-Yeon Yim, et al. Anesthetic management for a patient with severe mento-sternal contracture: difficul airway and scarce venous access -A case report-, Korean J Anesthesiol. 2013;64(1):61-64

31. American Society for Dermatological Surgery. Guiding principles for liposuction. Dermatol Surg. 1997;23:1127-1129.

32. Saraf S, Goyal P, Ranka P. Tumescent anaesthesia; a useful technique for harvesting split-thickness skin graft. Indian J Dermatol. 2004;49:184 186

33. Tanzer R. Burn contracture of the neck. Plast Reconstr Surg 1964;33:207-212.

34. Barraza-Espinoza V. Propanidido en México: mitos y realidades. Revista Mexicana de Anestesiología. 2017;40(1). 